\title{
Togitare
}

RELATO DE EXPERIÊNCIA

\section{EDUCAÇÃO PERMANENTE NA PRÁTICA DA ENFERMAGEM: INTEGRAÇÃO ENTRE ENSINO E SERVIÇO}

\author{
Valentina Barbosa da Silva ${ }^{1}$ (i) \\ Vanessa Alves Mendes ${ }^{1}$ (i) \\ Stéfane Christie Ferreira de Lima ${ }^{1}$ (1) \\ Thamyris Lucimar Pastorini Gonçalves ${ }^{1}$ (]) \\ Graciele Oroski Paes ${ }^{2}$ (i) \\ Marluci Andrade Conceição Stipp ${ }^{2}$ (i)
}

\section{RESUMO}

Objetivo: relatar a experiência da Educação Permanente em Saúde na formação de acadêmicos de enfermagem integrando o ensino com o serviço de enfermagem.

Desenvolvimento: relato de experiência sobre a prática de educação desenvolvida no hospital na capital de Rondônia, realizada no período entre abril e junho de 2019. Ela aconteceu em quatro momentos: troca de experiência entre os envolvidos; problematização das práticas; plano de intervenções; e avaliação. A implantação da educação permanente em saúde foi fundamental para a qualificação dos serviços, porém, registram-se dificuldades na execução, especialmente devido à forma da organização do trabalho hospitalar.

Conclusão: a educação permanente em saúde no estágio supervisionado permitiu a criação de espaços de reflexão com a equipe, contribuindo para a ampliação do diálogo, compreensão da realidade e inclusão de estratégias facilitadoras ao trabalho da enfermagem.

DESCRITORES: Enfermagem; Trabalho; Educação Continuada; Políticas de Saúde; Estratégias.

\section{EDUCACIÓN CONTINUA EN LA PRACTICA DE ENFERMERIA: INTEGRACIÓN ENTRE ENSENANZA Y SERVICIO}

\section{RESUMEN:}

Objetivo: relatar la experiencia de la educación continua en salud en la educación de estudiantes de enfermería integrando la enseñanza con el servicio de enfermería.

Desenvolvimiento: informe de experiencia sobre la práctica de educación desarrollada en el hospital de la capital de Rondônia, realizada entre abril y junio de 2019. Sucedió en cuatro momentos: intercambio de experiencias entre los involucrados; problematización de las prácticas; plan de intervención; y evaluación. La implementación de la educación continua en salud fue fundamental para la calificación de los servicios, sin embargo, hay dificultades en la ejecución, especialmente debido a la forma en que el trabajo hospitalario es organizado.

Conclusión: la formación continua en salud en las prácticas supervisadas permitió la creación de espacios de reflexión con el equipo, contribuyendo a la expansión del diálogo, la comprensión de la realidad y la inclusión de estrategias que faciliten el trabajo de enfermería. 
A educação permanente em saúde (EPS) constitui-se numa estratégia de aprendizagem no ambiente de trabalho, que incorpora o ato de aprender e ensinar ao cotidiano das organizações de saúde e ao processo de trabalho(1). Na enfermagem, a EPS pode promover o repensar das ações, favorecer a participação na tomada de decisão e a articulação entre os trabalhadores ${ }^{(2)}$.

O modelo de aprendizagem pautado na transmissão de conteúdo já não comporta a transformação das situações-problema advindas da prática dos serviços, tornando-se necessário superar a educação bancária, possibilitando a ampliação da qualidade do cuidado nos ambientes de trabalho na saúde ${ }^{(3)}$.

No Estado de Rondônia, o curso de enfermagem da Instituição Federal de Ensino (IFES) existe há 31 anos e, desde sua criação, utiliza unidades de saúde da rede pública municipal e estadual como cenário para ensino prático. Isso facilita a apreensão e o conhecimento do discente, pois vivencia situações reais do ambiente de trabalho.

Dentre os espaços de ensino prático, destaca-se o Hospital de Base (HB), referência em alta complexidade no estado. Nesse cenário, desenvolveu-se a disciplina obrigatória de Estágio Supervisionado II (ESII), ofertada no último período do curso de enfermagem para implementação de atividades gerenciais, assistenciais e educativas nos serviços de saúde.

Nesta vivência, a problemática se refere à ausência de estratégias para a integração do ensino com o serviço. Não existia um espaço para pausa, reflexão, leitura, planejamento e retorno das práticas com intervenções transformadoras e participativas ${ }^{(3)}$, o que impedia um caminhar com mais responsabilidade e compreensão da realidade do trabalho para os acadêmicos. Tornou-se urgente repensar ações de EPS integrando discentes, docentes e profissionais do HB.

Considerando que a integração do ensino com o serviço necessita de um olhar ampliado na formação acadêmica e na qualificação dos profissionais, questionamos: como a IFES, por meio da inserção de discentes e docentes do curso, pode contribuir com intervenções práticas e reflexivas ao trabalho da enfermagem, apropriando-se da EPS? A fim de responder essa inquietação, objetiva-se relatar a experiência da EPS na formação acadêmica integrando ensino e serviço dos profissionais de enfermagem.

Fundamentou-se na pesquisa translacional como caminho de aproximação das pesquisadoras do campo de prática. Essa pesquisa pode orientar o desenvolvimento de tecnologias e processos educacionais aplicáveis no cotidiano do trabalho de enfermagem através do compartilhamento do conhecimento ${ }^{(4)}$.

\section{DESENVOLVIMENTO}

Trata-se de uma estratégia educativa desenvolvida entre discentes, docentes e trabalhadores de enfermagem durante o ESII no HB em Rondônia realizada no período de 22/04 a 12/06 do ano de 2019 nos setores: Banco de Leite Humano (BLH); maternidade ala ginecológica e obstétrica (MGO) e o alojamento conjunto (ALCON), em cada setor uma acadêmica de enfermagem foi designada para desenvolver as competências necessárias do ESII. As docentes atuaram como facilitadoras dos encontros e das intervenções propostas.

A problematização foi utilizada como suporte metodológico ${ }^{(3)}$ e para a organização 
das atividades, dividimo-las em quatro momentos, dos quais participaram enfermeiras coordenadoras do BLH, MGO, ALCON; Núcleo de Educação Permanente (NEP); Gerência de Enfermagem (GE); Núcleo de Segurança do Paciente (NSP), discentes e docentes da IFES.

\section{Momento 1: Acolhimento e troca de experiências entre ciclos acadêmicos}

Primeiramente, foi realizada uma roda de conversa(5), denominada "Passagem de plantão compartilhada" entre os discentes que estavam encerrando o primeiro ciclo do ESII e as iniciantes do segundo. O objetivo foi compartilhar a realidade dos cenários de prática de ensino no HB, para posterior imersão.

\section{Momento 2: Problematização e discussão das Propostas de Intervenção (PI)}

Após 15 dias nos setores, houve encontro com os participantes no local de ensinoprática, foi compartilhado o diagnóstico situacional e perfil de cada cenário, assim, foram discutidos os problemas encontrados e a realidade dos setores.

\section{Momento 3: Elaboração e implementação das PI}

Após inserção nos setores, houve discussão do grupo sobre a metodologia, e implementaram-se as estratégias nos cenários definidos.

\section{Momento 4 - Avaliação a implementação nos cenários definidos}

Para avaliação, utilizou-se a pergunta disparadora: Quais as potencialidades e limites encontrados na implementação das PI?

No Momento 1, observou-se peculiaridades no cotidiano das práticas, quanto à rotina dos setores, padrão de aprazamento das medicações, rotatividade de usuários e inclusão nos diálogos disparados pelas discentes. A complexidade da EPS e os requisitos mínimos para sua efetividade exigiu preparo constante do grupo.

A aproximação da educação dos profissionais das práticas de atenção à saúde, gestão setorial e análise da organização social é fundamental, pois facilita a integração da formação (instituições de ensino), da gestão e atenção à saúde (gestores e trabalhadores de saúde) e da participação dos usuários (controle social)(1).

A troca de experiências foi construída com discussões ampliadas e participação dos trabalhadores de enfermagem, permitindo o protagonismo dos envolvidos na EPS, essenciais para exercício da autonomia. A problematização é importante para formação dos trabalhadores da saúde, pois aprendem no cotidiano do trabalho de suas experiências e dificuldades(3). Conforme a problematização, definiram-se as PI a seguir.

No ALCON, local com grande demanda e atenção específica para puérpera e recémnascido (RN), encontrou-se desafios como: poucas orientações da equipe de enfermagem sobre cuidados com o RN e manejo da amamentação, principalmente no momento da alta.

$\mathrm{Na}$ MGO, destacam-se os problemas: postergação nas atividades de enfermagem devido à falta de dimensionamento; alto índice glicêmico das usuárias; recursos materiais escassos; e erros na identificação e administração de medicamentos, sendo este último destaque principal da enfermeira do local.

No BLH, o problema foi o grande fluxo de atendimentos de intercorrências mamárias devido à falta de orientações, durante o pré-natal ou durante a assistência puerperal no ALCON do HB.

Diante das demandas, o grupo apropriou-se da teorização, por compreender que 
teoria e prática são imprescindíveis para resultados concretos e positivos ${ }^{(3)}$, elaborando como propostas: No ALCON - Plano de Alta para puérperas; na MGO - criação de Protocolo Operacional Padrão (POP) sobre erros de medicação; no BLH - elaboração de instrumento para o manejo clínico do AM para usuárias e RN internos no ALCON.

Nas reuniões, foram discutidos os problemas e a aplicabilidade para continuidade das PIs. Retornando à prática, percebeu-se a viabilidade da EPS com os trabalhadores de enfermagem. Salienta-se que todas as Pls foram bem recebidas pelas equipes, que demonstraram interesse em realizar as intervenções.

$\mathrm{Na}$ aplicação, as dificuldades foram: comunicação ineficaz entre os cenários, principalmente o ALCON e BLH, causando superlotação e sobrecarga dos trabalhadores do $\mathrm{BLH}$; fragilidade na corresponsabilização sobre as práticas educativas nos setores, dificultando a disseminação das estratégias de EPS; e resistência às mudanças, principalmente dos mais experientes.

Todavia, as rodas de conversa foram estratégias facilitadoras e significativas no desenvolvimento da EPS, proporcionando o compartilhamento das experiências, aproximando os trabalhadores dos problemas existentes no cotidiano do trabalho em saúde, assim como das práticas assistenciais inadequadas, e por fim, estabeleceu novos parâmetros para a aprendizagem e saber ${ }^{(5)}$. Além disso, a EPS aliada à pesquisa translacional surge como método de trabalho estruturado, eficaz, capaz de produzir discussões, abordando aspectos que contribuem com a aprendizagem, transformação profissional e formação das acadêmicas ${ }^{(4-7)}$.

O trabalho participativo foi primordial para execução das atividades, pois, dentre as competências existentes para execução das Pls, é essencial que o enfermeiro gerencie a assistência, desenvolva atividades administrativas, educativas e de pesquisa, com objetivo de melhorar a prática assistencial. As conversas diárias com o enfermeiro demonstraram significativa importância no processo, pois é o profissional que possui papel de liderança ${ }^{(7)}$.

No sentido avaliativo, os trabalhadores entenderam que as PIs estavam bem estruturadas e pautados na realidade dos setores, sendo factível e viável desenvolvê-los. Por tal motivo, o NEP solicitou que as PIs fossem institucionalizadas na rotina hospitalar, e executadas em conjunto com as equipes.

Entende-se que as discussões das PIs foram relevantes para o crescimento profissional das acadêmicas. Oportunizaram o desenvolvimento das práticas alicerçadas nas prioridades de cada cenário, a reflexão acerca das práticas assistenciais e, portanto, a realização com excelência do ESII.

A avaliação do processo formativo busca o aperfeiçoamento das ações, reorientação e recondução dos processos ${ }^{(8)}$. Trata-se de um momento de fundamental importância na análise dos resultados obtidos, que promove a reflexão dos educadores e educandos sobre fragilidades e potencialidades das propostas educativas e pode subsidiar proposições de açồes com maior efetividade ${ }^{(9)}$. O diálogo e o feedback dos momentos foram pontos fortes que facilitaram a execução das Pls e avaliação das estratégias.

A translação do conhecimento aproximou-se das necessidades científicas atuais, proporcionando o diálogo entre saberes ${ }^{(4)}$. Desta forma, a pesquisa translacional facilitou a integração entre ensino-pesquisa e serviço, considerando o conteúdo aplicado, o método, o espaço, o contexto, potencializando o cuidado seguro e a qualificação do trabalho de enfermagem. 
O processo de implementação da EPS elucidou desafios que precisam ser superados para tornar-se um processo permanente e continuado, sendo o principal a falta de tempo dos profissionais, que precisam decidir entre trabalho assistencial e aprendizado, e poucas estratégias de reflexão que facilitem a aplicabilidade das Pls.

O vínculo estreito entre a comunidade científica e serviço gera resultados em que todos são beneficiados: os acadêmicos por ter a possibilidade de aprender na prática, o serviço por ter oportunidade de receber suporte teórico atualizado e, sobretudo, o usuário, que recebe boa assistência. A EPS precisa estar inserida na carga horária contratual do trabalhador, facilitando a participação de todos.

\section{REFERÊNCIAS}

1. Lemos CLS. Educação Permanente em Saúde no Brasil: educação ou gerenciamento permanente? Ciênc. saúde coletiva. [Internet]. 2016 [acesso em 11 ago 2019]; 21(3). Disponível em: http://dx.doi. org/10.1590/1413-81232015213.08182015.

2. Fagundes NC, Rangel AGC, Carneiro TM, Castro LMC, Gomes B dos S. Educação permanente em saúde no contexto do trabalho da enfermeira. Rev Enferm UERJ [Internet]. 2016 [acesso em 18 nov 2019]; 24 (1). Disponível em: https://www.e-publicacoes.uerj.br/index.php/enfermagemuerj/article/ view/11349/17855.

3. Freire P. Pedagogia do oprimido. 17. ed. Rio de Janeiro: Paz e Terra; 1968.

4. Olegário RL, Vitorino SMA, Souza PVN de. Pesquisa translacional do ensino superior no campo das ciências da saúde. RIR [Internet]. 2019 [acesso em 12 dez 2019]; 15(2). Disponível em: https://revistas.ufg. br/rir/article/view/56988.

5. Lavich CRP, Terra MG, Mello A de L, Raddatz M, Arnemann CT. Ações de educação permanente dos enfermeiros facilitadores de um núcleo de educação em enfermagem. Rev. Gaúcha Enferm. [Internet]. 2017 [acesso em 23 jan 2020]; 38(1). Disponível em: https://doi.org/10.1590/1983-1447.2017.01.62261.

6. Adamy EK, Zocche DA de A, Vendruscolo C, Metelsky FK, Argenta C, Valentini J dos S. Tecendo a educação permanente em saúde no contexto hospitalar: relato de experiência. Rev Enferm. Centro-Oeste Mineiro. [Internet]. 2018 [acesso em 22 dez 2019]; 8. Disponível em: http://seer.ufsj.edu.br/index.php/ recom/article/view/1924.

7. Amestoy SC, Oliveira AFL de, Thofehrn MB, Trindade L de L, Santos BP dos, Bao ACP. Contribuições freirianas para entender o exercício da liderança dialógica dos enfermeiros no ambiente hospitalar. Rev. Gaúcha Enferm [Internet]. 2017 [acesso em 21 jan 2020]; 38(1). Disponível em: http://dx.doi. org/10.1590/1983-1447.2017.01.64764.

8. Dalcól C, Garanhani ML, Fonseca LF, Carvalho BG. Competência em comunicação e estratégias de ensino-aprendizagem: percepção dos estudantes de enfermagem. Cogitare enferm. [Internet]. 2018 [acesso em 20 jan 2020]; 23(3). Disponível em: http://dx.doi.org/10.5380/ce.v23i3.53743.

9. Silva LAA da, Schmidt SMS, Noal HC, Signor E, Gomes IEM. Avaliação da educação permanente no processo de trabalho em saúde. Trab. Educ. Saúde. [Internet]. 2016. [acesso em 8 out 2019]; 14(3). Disponível em: http://dx.doi.org/10.1590/1981-7746-sol00015. 
COMO REFERENCIAR ESTE ARTIGO:

Silva VB da, Mendes VA, Lima SCF de, Gonçalves TLP, Paes GO, Stipp MAC. Educação permanente na prática da enfermagem: integração entre ensino e serviço. Cogitare enferm. [Internet]. 2021 [acesso em "colocar data de acesso, dia, mês abreviado e ano"]; 26. Disponível em: http://dx.doi.org/10.5380/ce.v26i0.71890.

Recebido em: 23/02/2020

Aprovado em: 09/09/2020

Autor Correspondente:

Valentina Barbosa da Silva

Universidade Federal de Rondônia - Porto Velho, RO, Brasil

E-mail: vallentinna2@gmail.com

Contribuição dos autores:

Contribuições substanciais para a concepção ou desenho do estudo; ou a aquisição, análise ou interpretação de dados do estudo - SCFL, TLPG

Elaboração e revisão crítica do conteúdo intelectual do estudo - VAM

Aprovação da versão final do estudo a ser publicado - GOP, MACS

Responsável por todos os aspectos do estudo, assegurando as questões de precisão ou integridade de qualquer parte do estudo - VBS

Copyright () 2021 Este é um artigo em acesso aberto distribuído nos termos da Licença Creative Commons Atribuição, que permite o uso irrestrito, a distribuição e reprodução em qualquer meio desde que o artigo original seja devidamente citado. 